\title{
KHẢO SÁT GIẢI PHẪU ĐộNG MACH XUYÊN ĐộNG MẠCH ĐÙI SÂU QUA PHẤU TÍCH XÁC
}

\section{TÓM TẮT}

Đặt vấn đề: Vạt da động mạch xưyên là một trong các chất liêu quan trọng trong phẫu thuât tạo hình, việc bộc lộ các động mạch xuyên vẫn còn là thách thức đối với các phâuu thuât viên. Để hiểu rõ về vạt động mạch xuyên động mạch đùi sâu, vạt rất hữu ích trong phẫu thuât tạo hình che phủ khuyết hổng vùng ụ ngồi, mấu chuyển lớn chúng tôi tiến hành nghiên cứu: "Khảo sát giải phẫu động mạch xuyên động mạch đùi sâu qua phẫu tích xác. Đối tượng và phương pháp: Nghiên cứu tiến cứu mô tả cắt ngang hàng loạt catrên 17 xác được tẩm formol và bảo quản trong phòng lanh với 31 vat da vùng đùi sau. Trên xác các động mạch xuyên động mạch đùi sâu được phẫu tích theo một quy trình thống nhất. Các giới hạn đường rạch da để bộc lộ các động mạch xuyên động mach đùi sâu: Phía trên: đường ngang qua nếp mổng dưới, phía dưới: đường ngang qua hố khoeo, phía ngoài: đường nối lồi câuu ngoài xương đùi với mấu chuyển lớn, phía trong: đường nối ngành dưới xương mu và đỉnh lồi cầu trong xương đùi. Bộc lộ động mạch xuyên động mạch đùi sâu. Đo các mốc giải phẫu và kích thước động mach xuyên bằng thước chuyên dùng (Palmer). Kết quả: Động mạch xuyên I và II xuất hiện hầu hết ở $1 / 2$ trên đường chuẩn đích với cách biểt trong khoảng $3 \mathrm{~cm}$ về hai phía đường chuẩn đích. Động mạch xuyên I có tần suất xuất hiện về phía ngoàiđường chuẩn đích (cả bên đùi phải lẫn đùi trái) gấp khoảng 7 lần (27 so vơi 4) so với phía trong đường chuẩn đích. Đông mach xuyên IV được phát hiện chỉ có 5 trường hợp ở vùng đùi sau, thấp nhất với tỷ lê $16,13 \%$. Đống mach xuyên có đường kính 1$2 \mathrm{~mm}$ chiếm tỷ lệ cao trong đó động mạch xuyên I chiếm tỷ lê cao nhất $54,83 \%$. Động mạch xuyên có chiều dài $15-30 \mathrm{~mm}$ chiếm tỷ lệ cao đặc biệt ở động mach xuyên I và II $(64,52 \%$ và $70,97 \%)$. Khoảng cách trung bình từ động mạch xuyên I đến mấu chuyển lớn $157,39 \pm 38,12 \mathrm{~mm}$ và đến ụ ngồi 127,93 $\pm 37,87$ mm. Kết luận: Vạt da động mạch xuyên I động mạch đùi sâu phù hợp trong tạo hình che phủ khuyết hổng vùnq u nqồi, mấu chuyển lớn.

Tư khóa: Động mạch xuyên động mạch đùi sâu, vat da đùi sau

\section{SUMMARY}

ANATOMICAL STUDY PERFORATOR OF DEEP FEMORAL ARTERY BY CADAVER DISSECTION

Background: The cutaneous perforrator flap is one of the important materials in plastic surgery,

*Viện Bỏng Quốc gia, Học viện Quân y

Chịu trách nhiệm chính: Đặng Xuân Quang

Email: drhung1955@gmail.com

Ngày nhận bài: $15 / 1 / 20221$

Ngày phản biên khoa hoc: $5 / 2 / 2021$

Ngày duyệt bài: $2 / 3 / 2021$ revealing these branches remains a challenge for surgeons. In order to understand clearly about the cutaneous branches of the deep femoral artery, the flaps which are very useful in surgery to cover the defects of the ischium tuberosity, greater trochanter region, we conduct research on the subject: "Anatomical study perforator of deep femoral artery by cadaver dissection" Materials and methods: Study of prospective, cross section and series case. Sample study on 17 cadavers were impregnated with formol and stored in cold room include 31 cutaneous posterior thigh flaps. On the cadaver the penetrating branches of the deep femoral artery were disseted according to a unified procedure. The limit skin incisions to discover perforators of deep femoral artery are superiorly: horizontal line across the inferior gluteal fold, inferior: from line across popliteal fossa laterally: a line connecting frome lateral condyle of femur to greater trochanter, medially: a line connecting frome inferior pulic ramus to medial condyle of femur. Discover the perforator branches of deep femoral artery. Measure anatomical landmarks and size of perforator branches by using Palmer ruler. Results: Branches I and II appear mostly in $1 / 2$ superior reference line with a distance of about $3 \mathrm{~cm}$ on both sides of reference line. Branch I have a occurence frequency on the lateral side of reference line is 7 times more than ( 27 vs. 4) medial side reference line in both side. The perforator IV was found 5 cas on lateral thigh, in which smallest rate $16.13 \%$. The perforator has a diameter of $1-2 \mathrm{~mm}$ accounting for a high proportion, in which the branch I accounts for the highest rate $54.83 \%$. The perforator has the length of $15-30 \mathrm{~mm}$ accounting for a high proportion, especially of the branch I and II $(64.52 \%$ and $70.97 \%$ ). The average distance from perforator I to greater trochanter is $157.39 \pm 38.12 \mathrm{~mm}$ and to ischium is $127.93 \pm 37.87 \mathrm{~mm}$. Conclusion: The perforator flaps of deep femoral artery are suitable for plastic surgery to cover the ischium and greater trochanter defects.

Keyword: Perforator of deep femoral artery, posterior thighskin flap.

\section{I. ĐĂT VẤN ĐỀ}

ư ngồi, mấu chuyển lớn là vị trí dễ tổn thương gây loét bề mặtvàbộc lộ xương.Tái tạo da mô vùng giải phẫu này không chỉ có yêu cẩu che phủ mà còn có yêu câu các vạt da ghép có khả năng chịu được lực tì đè, bảo tồn chức năng các cơ và không làm hoại tử vùng cho vạt da.

Từ sau quan điểm vạt cân da của Pontén [1] 1981 được đa số các tác giả đồng thuận, nhiêu tác giả đã bắt đầu nghiên cứu động mạch xuyên động mach ở nhiều đoạn chi khác nhau của cơ thể đặc biệt ở vùng sau đùi. Xuất phát từ thực tế 
trên và với mong muốn góp phần xây dựng quy trình điều trị an toàn, hiệu quả, phù hợp nhất cho bệnh nhân người Việt Nam bị loét ụ ngồi, mấu chuyển lớn, chúng tôi tiến hành nghiên cứu: "Khảo sát giải phẫu động mạch xuyên động mạch đùi sâu qua phẫu tích xác"

\section{II. Đốl TƯợNG, VẬT LIỆU VÀ PHƯƠNG PHÁP NGHIÊN CỨU}

2.1. Đối tượng nghiên cứu: nghiên cứu được tiến hành trên 17 xác được tẩm formol và bảo quản trong phòng lạnh tại Bộ Môn Giải Phẫu Đại Học Y Dược Thành Phố Hồ Chí Minh với 31 vạt da vùng đùi sau. Trên xác các động mạch xuyên động mạch đùi sâu được phẫu tích theo một quy trình thống nhất.

2.2. Phương pháp nghiên cứu. Tiến cứu mô tả cắt ngang hàng loạt trường hợp phẫu tích xác

Các giới hạn đường rạch da để bộc lộ các động mạch xuyên động mạch đùi sâu: phía trên: đường ngang qua nếp mông dưới, phía dưới: đường ngang qua hố khoeo, phía ngoài: đường nối lồi cầu ngoài xương đùi với mấu chuyển lớn (đường chuẩn đích), phía trong: đường nối ngành dưới xương mu và đỉnh lồi câu trong xương đùi. Bộc lộ các động mạch xuyên động mạch đùi sâu. Đo các mốc giải phẫu và kích thước động mạch xuyên bằng thước chuyên dùng (Palmer) (hình 1).

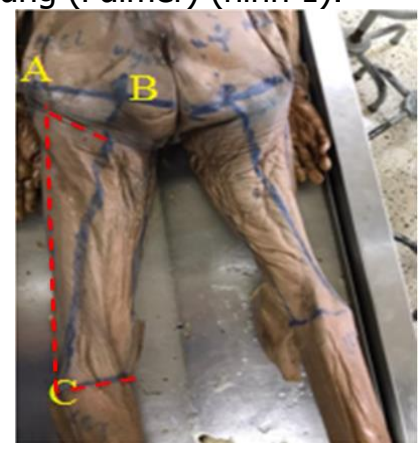

\subsection{Các bước tiến hành:}

- Phẫu tích xác bộc lộ động mạch xuyên động mạch đùi sâu

- Đo các mốc giải phẫu và kích thước động mạch xuyên bằng thước chuyên dụng.

- Lập bảng biểu

- Phân tích số liệu: phần mềm SPSS 20.0

\section{KẾT QUẢ NGHIÊN CứU}

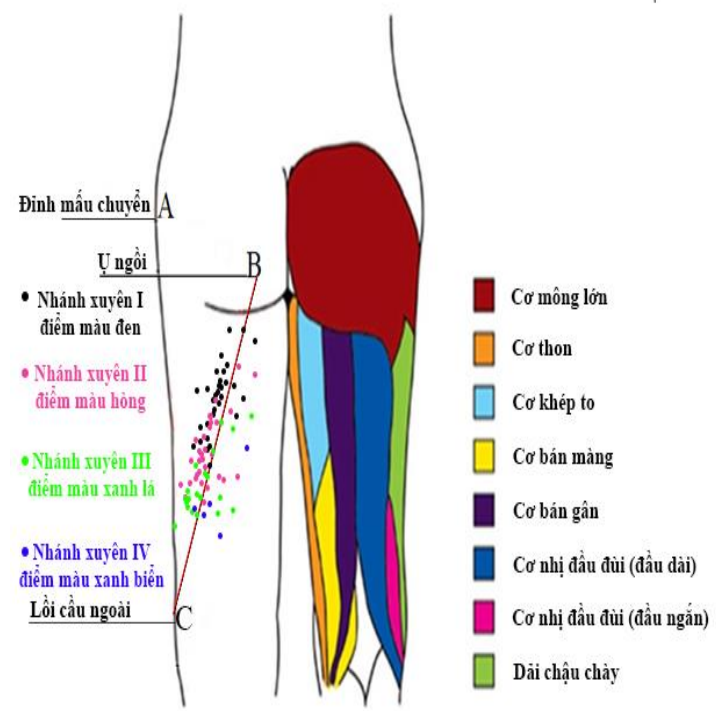

Hình 2. Sơ đồ các động mạch xuyên ra da.

Bảng 1. Tỷ lệ các động mạch xuyên được phát hiện $(\boldsymbol{n}=\mathbf{3 1})$

\begin{tabular}{|c|c|c|c|c|}
\hline $\begin{array}{c}\text { Động mạch } \\
\text { xuyên }\end{array}$ & I & II & III & IV \\
\hline Tân suất & & & & \\
\hline Số tiêu bản & 31 & 31 & 20 & 5 \\
\hline Tý lệ (\%) & 100 & 100 & 64,5 & 16,13 \\
\hline
\end{tabular}

Nhận xét: - Động mạch xuyên I và II được phát hiện trong toàn bộ 31 vùng đùi sau, chiếm tỷ lệ 100\%

- Động mạch xuyên IV được phát hiện chỉ ở 5 vùng đùi sau, thấp nhất với tỷ lệ (5/31) 16,13\%.

Bảng 2. Đường kính động mạch xuyên ( $\mathrm{n=31}$ )

\begin{tabular}{|c|c|c|c|c|}
\hline xuyên & $\begin{array}{c}0,4-0,99 \mathrm{~mm} \\
\mathrm{n} / \%\end{array}$ & $\begin{array}{c}1-2 \mathrm{~mm} \\
\mathrm{n} / \%\end{array}$ & $\begin{array}{c}>2 \mathrm{~mm} \\
\mathrm{n} / \%\end{array}$ & Trung bình \\
\hline$I(n=31)$ & 8 mâu $(25,8 \%)$ & 17 mâu $(54,83 \%)$ & 6 mâu(19,35\%) & $1,43 \pm 0,67 \mathrm{~mm}$ \\
\hline II $(n=31)$ & 10 mấu(32,25\%) & 14 mầu $(45,16 \%)$ & 7 mấu(22,58\%) & $1,47 \pm 0,8 \mathrm{~mm}$ \\
\hline III $(n=20)$ & 7 mấu $(35 \%)$ & 6 mầu(30\%) & 7 mầu (35\%) & $1,69 \pm 0,94 \mathrm{~mm}$ \\
\hline IV $(n=5)$ & 1 mầu (20\%) & 1 mầu (20\%) & 3 mấu $(60 \%)$ & $2,28 \pm 0,87 \mathrm{~mm}$ \\
\hline
\end{tabular}

Nhận xét: - Đường kính trung bình động mạch xuyên I và II được xem là tương đương $(1,43 /$ $1,47 \mathrm{~mm}$ )

- Đường kính trung bình của động mạch xuyên IV lớn nhất so với các nhánh còn lại $(2,28 \mathrm{~mm})$

- Động mạch xuyên đường kính 1-2mm chiếm tỷ lệ cao trong đó động mạch xuyênI chiếm tỷ lệ cao nhất 54,83\%. 
Bảng 3. Chiều dài đông mậh xuyên (n=31)

\begin{tabular}{|c|c|c|c|c|}
\hline ĐM xuyên Chiều dài & $8-14,99 \mathrm{~mm}$ & $15-30 \mathrm{~mm}$ & $>30 \mathrm{~mm}$ & $\begin{array}{c}\text { Trung } \\
\text { bình }\end{array}$ \\
\hline I $(n=31)$ & 10 mấu(3 & 20 mầu(64,52\%) & 1 mầu(3,23\%) & $18,93 \pm 6,21 \mathrm{~mm}$ \\
\hline II $(n=31)$ & 8 mầu $(25,8 \%)$ & 22 mầu $(70,97 \%)$ & 1 mầu( $3,23 \%)$ & $18,45 \pm 5,62 \mathrm{~mm}$ \\
\hline III $(n=20)$ & 6 mâu $(30 \%)$ & 14 mâu $(70 \%)$ & 0 mấu & $17,72 \pm 6,52 \mathrm{~mm}$ \\
\hline IV $(n=5)$ & 2 mấu $(40 \%)$ & 3 mầu (60\%) & 0 mầu & $15,38 \pm 5,24 \mathrm{~mm}$ \\
\hline
\end{tabular}

Nhân xét: - Động mạch xuyên I có chiều dài trung bình lớn nhất tính từ nơi thoát ra ở cơ khép lớnra da $(18,93 \mathrm{~mm})$

- Động mạch xuyên có chiều dài $15-30 \mathrm{~mm}$ chiếm tỷ lệ cao đặc biệt ở động mạch xuyên I và II $(64,52 \%$ và $70,97 \%)$

Bảng 4. Khoảng cách điểm động mạch xuyên I ra da đến mấu chuyển lớn, ụ ngồi điểm động mạch xuyên III hoặc IV ra da đến lồi cầu ngoài $(n=25)$

\begin{tabular}{|c|c|c|}
\hline Khoảng cách & Khoảng thay đổi $(\mathrm{mm})$ & Trung bình $(\mathrm{mm})$ \\
\hline Từ động mạch xuyên I đến mấu chuyển lớn & $91,02-251,71$ & $157,39 \pm 38,12$ \\
\hline Từ động mạch xuyên I đến ụ ngồi & $61,55-221,51$ & $127,93 \pm 37,87$ \\
\hline $\begin{array}{c}\text { Từ động mạch xuyênIII (IV) đển lồi cầu } \\
\text { ngoài xương đùi }\end{array}$ & $94,13-252,29$ & $153,84 \pm 36,65$ \\
\hline
\end{tabular}

Nhận xét: - Khoảng cách trung bình từ động mạch xuyên I đến mấu chuyến lớn > khoảng cách trung bình từ nhánh này đến ụ ngồi (tương đương $30 \mathrm{~mm}$ )

- Khoảng cách trung bình phù hợp trong tạo vạt động mạch xuyên che phủ khuyết hổng vùng gối và khuỷu chân.

\section{BÀN LUÂN}

- Vùng chuẩn đích xác định động mạch xuyên: động mạch xuyên I và II xuất hiện hầu hết ở $1 / 2$ trên đường chuẩn đích với sai số khoảng $5 \mathrm{~cm}$ vê hai phía trái, phải. Trong nghiên cứu của Algan S. và cộng sự (2020) [2] cho thấy "Các vạt động mạch xuyên động mạch đùi sâu" trên 11 tiêu bản vùng đùi sau của xác bảo quản lạnh cho thấy phần lớn các động mạch xuyên động mạch đùi sâu xuất hiên trển bề măt da nằm trên cơ nhi đầu đùi, cơ bán gân. Kết quả nghiên cứu của chúng tôi và Algan S. là tương đương.

- Số lượng động mạch xuyên ít nhất là 2 nhánh và nhiều nhất là 4 nhánh trên tiêu bản xác. Các động mạch xuyên được xếp theo thứ tự trục từ trên xuống trên giải phẫu với tỷ lệ phát hiện động mạch xuyên I và II là $100 \%$, tỷ lệ phát hiện động mạch xuyên III $56 \%$ và động mạch xuyên IV 12\% (trên 3 tiêu bản). Song Y.G. và cộng sự (1984) [3] trong nghiên cứu: "Quan điểm vạt tự do mới ở động mạch vách da" cho thấy động mạch đùi sâu cung cấp 4 động mạch xuyên được xếp gần như thẳng hàng từ trên xuống dưới để cấp máu cho các cơ sau đùi. Mỗi động mạch xuyên kết thúc như là nhánh da đến bờ sau đùi. Kết quả nghiên cứu của chúng tôi và Song Y.G. là tương đương

- Đường kính ngọn trung bình giữa MDCT và phẫu tích xác $(1,14 / 1,17)$. Hai kết quả này được xem tương đương nhau. Shimizu $T$. và cộng sự (1997) [4] trong nghiên cứu: "So sánh giải phấu các vat vách da tự do ở vùng đùi" với phẫu tích 42 xác tươi gồm 17 phái nữ và 6 phái nam sau khi chích latex vào động mạch đùi. Kết quả cho thấy đường kính trung bình động mạch xuyên I là $1,5 \pm 0,2 \mathrm{~mm}$. Đường kính trung bình động mạch xuyên II là $1,5 \pm 0,2 \mathrm{~mm}$. Kết quả nghiên cứu của chúng tôi và Shimizu T. là tương đương

- Các chiều dài động mạch xuyên từ lớp cân nông ra đến da trung bình gần $20 \mathrm{~mm}$ có ở cả 4 nhánh. Ahmadzadeh R. và cộng sự (2007) [5] trong nghiên cứu: "Vạt da động mạch xuyên động mạch đùi sâu" với 11 tiêu bản vùng đùi sau dùng trong nghiên cứu, chích oxide chì và gelatin vào trong động mạch, qua đó xác định các động mạch xuyên động mạch đùi sâu cho thấy chiều dài động mạch xuyên trung bình tính từ lớp cân là $29 \pm 14 \mathrm{~mm}$. Kết quả nghiên cứu của chúng tôi và Ahmadzadeh $R$. là tương đương

\section{KẾT LUÂ̂N}

- Động mạch đùi sâu cho 4 động mạch xuyên với động mạch xuyên I và II luôn xuất hiện với tỷ lệ $100 \%$ trong khảo xác.

- Động mạch xuyên I và II xuất hiện hầu hết ở $1 / 2$ trên đường chuẩn đích phần đùi sau ngoài với sai số khoảng $3 \mathrm{~cm}$.

- Động mạch xuyên có đường kính 1-2mm chiếm tỷ lệ cao trong đó động mạch xuyên I chiếm tỷ lệ cao nhất 54,83\%.

- Động mạch xuyên có chiều dài $15-30 \mathrm{~mm}$ chiếm tỷ lệ cao đặc biệt ở động mạch xuyên I và 
II $(64,52 \%$ và 70,97\%).

- Khoảng cách động mạch xuyênI động mạch đùi sâu đến ụ ngôi, mấu chuyển lớn rất phù hợp trong việc tạo vạt da động mạch xuyênđộng mạch đùi sâu che phủ khuyết hổng.

\section{TÀI LIÊU THAM KHẢO}

1. Pontén B. The fasciocutaneous flap: its use in soft tissue defects of the lower leg. Br J Plast Surg. $1981 ; 34: 215-202$.

2. Algan S., el at. (2020). Profunda femoris artery perforator flaps: a detailed anatomical study.
Journal of Plastic Surgery and Hand Surgery. 1-5.

3. Song Y.G., Chen G.Z., Song Y.L. (1984). The free thigh flap: a new free flap concept based on the septocutaneous artery. Br J Plast Surg., 37:149-159.

4. Shimizu T., Fisher DR., Carmichael SW., et al. (1997). An anatomic comparison of septocutaneous free flaps from the thigh region. Ann Plast Surg. 38:604-610.

5. Reza Ahmadzadeh, B.Sc, Leonard Bergeron, M.D. The Posterior Thigh Perforator Flap or Profunda Femoris Artery Perforator Flap. page 196 - 197. Copyright American Society of Plastic Surgeons.

\section{CƯỜNG GIÁP DO VIÊM TUYẾN GIÁP HASHIMOTO Ở TRẺ EM}

\section{TÓM TẮT}

Viêm tuyến giáp Hashimoto (HT) là bệnh lý tuyến giáp mắc phải gây bướu cổ phổ biến ở trẻ em. Đăc trưng lâm sàng của bênh là tình trang suy giáp tiến triển dần dần. Tuy nhiền, bệnh có thể biểu hiện triệu chứng cường giáp trong một giai đoạn thoáng qua (Hashitoxicosis). Mục tiều: Mô tả đặc điểm lâm sàng, xét nghiêm và điều tri của bênh nhân cường giáp do HT. Đối tượng: 39 bệnh nhân cường giáp do HT được chẩn đoán và điều trị tai khoa Nội tiết - Chuyển hóa - Di truyền, Bệnh viện Nhi Trung ương từ 01/2018 đến 12/2019. Phương pháp: Nghiên cứu một loạt ca bệnh bao gôm mô tả đặc điểm lâm sàng, xét nghiêm chức năng tuyến giáp xét nghiêm miễn dịch và điều trị. Kết quả: 39 bệnh nhân được chẩn đoán cường giáp do HT, tuổi trung bình là $9,75 \pm 2,22$ tuổi. Lý do khám bệnh hay gặp nhất là bướu cổ. Tất cả các bệnh nhân được điêu trị Thiamazole; 26 bênh nhân được điều trị Propranolol. Kết luân: Bướu cổ là triệu chứng hay gặp nhất, tỉ lệ mắc bệnh ở nữ nhiều hơn nam. Xác đinh nguyên nhân cường giáp là quan trong. Kháng thể kháng giáp là xét nghiệm quan trọng giúp phát hieên, theo dõi, tiên lượng bệnh.

Tư khóa: Viêm tuyến giáp Hashimoto trẻ em, cường giáp, viêm tuyến giáp tự miễn.

\section{SUMMARY}

HYPERTHYROIDISM CAUSED BY HASHIMOTO'S THYROIDITIS IN CHILDREN

Hashimoto's thyroiditis is one of the most common acquired thyroid disorders with goiter in children. It is characterized clinically by gradual hypothyroidism, however, hyperthyroidism sometimes can be one of clinical manifestations in early course of disease (Hashitoxicosis). Aims: to describe clinical characteristics, biochemical tests and treatment in 39

*Bênh viên Nhi Trung Ương

Chịu trách nhiệm chính: Vũ Chí Dũng

Email: dungvu@nch.org.vn

Ngày nhân bài: 28.12.2020

Ngày phản biên khoa hoc: 15.2.2021

Ngày duyệt bài: 25.2.2021

\section{Nguyễn Trọng Thành*, Vũ Chí Dũng*}

patients diagnosed with Hashitoxicosis. Subjectives: Patients diagnosed with Hashitoxicosis treated in Endocrinology - Metabolism - Genetic Department at the Vietnam National Children's Hospital from January 2018 to December 2019. Methods: case series study. Results: there were totally 39 patients diagnosed with Hashitoxicosis. Their mean age was $9.75 \pm 2.22$ years. Common complaints were goiter. All patients were treated with Thiamazole (Thyrozol) and 26 out of 39 patients received Propranolol. Conclusions: Goiter was the most common complaint. Morbidity rate was higher in girls than boys. It is essential to identify the cause in approaching to a patient who presents signs and symptoms of hyperthyroidism.

Keywords: Hashimoto's thyroiditis in children, hyperthyroidism, autoimmune thyroiditis.

\section{I. ĐĂT VẤN ĐỀ}

Viêm tuyến giáp Hashimoto là bệnh lý tuyến giáp tự miến phổ biến nhất ở trẻ em, còn gọi là viêm tuyến giáp lympho man tính. Trong phần lớn các trường hợp nếu không được điều trị, bệnh sẽ tiến triển dần dần và cuối cùng dẫn đến suy giáp. Tuy nhiên, bệnh có thể biểu hiện ở trạng thái bình giáp, thậm chí cường giáp ở một giai đoạn nhất định trong quá trình tiến triển của bệnh [1]. Tình trạng cường giáp được coi là giai đoạn đầu của viêm tuyến giáp Hashimoto Hashitoxicosis. Chẩn đoán xác định dựa vào sự xuất hiện của kháng thể kháng tuyến giáp trong máu (chủ yếu là thyroperoxidase và thyroglobulin), kèm theo siêu âm tuyến giáp cho thấy hình ảnh nhu mô giảm âm ở những bệnh nhân có biểu hiện lâm sàng [2]. Trên lâm sàng, các trường hợp cường giáp do HT có thể bị bỏ qua do các triệu chứng tiến triển từ từ và không đăc hiêu, trong đó bướu cổ là triệu chứng phổ biến nhất. Tuy nhiên, đôi khi các triệu chứng của bệnh có thể rất điển hình và đòi hỏi cần được can thiệp sớm. Viêm tuyến giáp do HT có thể 